\title{
The Patterning of Collaborative Behavior and Knowledge Culminations in Interdisciplinary Research Centers
}

\author{
Elina I. Mäkinen ${ }^{1}$ (D) Eliza D. Evans ${ }^{2} \cdot$ Daniel A. McFarland ${ }^{2}$
}

Published online: 3 July 2019

(C) The Author(s) 2019

\begin{abstract}
Due to investments in interdisciplinary research endeavors, the number and variety of interdisciplinary research centers have grown exponentially during the past decades. While interdisciplinary research centers rely on varied organizational arrangements, we know little about the conditions and processes that mediate collaborative arrangements and interdisciplinary research outcomes. This study examines how different collaborative arrangements shape scholars' experiences of interdisciplinary research and understandings of interdisciplinary knowledge culminations in the context of university-based research centers. We conducted three indepth qualitative case studies on different centers, which recruited researchers from natural sciences, medicine, and social sciences. We refer to them as the Biotech Center, the Environmental Center, and the Premature Birth Center. Our analysis of 53 interviews with interdisciplinary scholars across the three centers demonstrates that the scholars perceive particular features of the centers' collaborative arrangements as meaningful for interdisciplinary collaboration. Specifically, the center's mission, physical architecture, and leadership and task structure were seen as affecting scholars' motivation, interaction, and inclusion in the centers, which then shaped the interdisciplinary knowledge culminations. At the Biotech Center, knowledge was
\end{abstract}

This article is dedicated to our friend, colleague, and coauthor, Eliza D. Evans, who passed away before seeing our work in print. We miss her and cherish her memory.

Elina I. Mäkinen

elina.makinen@tuni.fi

Eliza D. Evans

eliza.evans@stanford.edu

Daniel A. McFarland

mcfarland@stanford.edu

1 Faculty of Management and Business, Tampere University, Tampere, Finland

2 Graduate School of Education, Stanford University, Stanford, USA 
translated towards concrete products, at the Environmental Center knowledge was pooled together from varied fields to create new problem framings, and at the Premature Birth Center, interdisciplinary collaboration was crafted through top-down knowledge brokerage.

Keywords Interdisciplinary research · Research centers · Collaboration · Scientists $\cdot$ Collaborative arrangements

\section{Introduction}

Academic institutions across the world seek ways to combine knowledge across different disciplines through an interdisciplinary research approach. This is due to the idea that mixing experts from different fields of research can lead to innovation, creativity, and the identification of more powerful solutions to society's most persistent and complex problems (e.g., Bruce et al. 2004; Boix Mansilla 2006; Klein 2010; Leahey and Montgomery 2011). Some have contested the suggested benefits and even the newness of interdisciplinarity (e.g., Jacobs 2013; Graff 2015). Jacobs (2013), for example, argued that academic knowledge is able to move across disciplinary boundaries and, as such, there is little need to invest in interdisciplinary research approaches. In his view, universities should focus on promoting research specialization as distinct fields of research that could similarly advance knowledge on a given complex problem.

The debate regarding whether interdisciplinary is good or bad for advancing knowledge creation and solving complex problems is ongoing. Still, academic institutions, foundations, and governments have heavily invested in interdisciplinary research (Boix Mansilla 2006; Jacobs and Frickel 2009). These investments have resulted in new educational programs, grants, and research centers across the world (Geiger 1990; Bruce et al. 2004; National Academies 2005; Hackett and Rhoten 2009). In this study, we examine the role of research centers in the realization of interdisciplinary knowledge creation. Centers are the result of universities' efforts to promote interdisciplinarity by developing cross-disciplinary topic-focused centers and they provide a legitimate space for scholars interested in exploring knowledge creation beyond the boundaries of their disciplines (Biancani et al. 2014).

The task of interdisciplinary research centers is not easy, however. Academic knowledge production tends to occur within disciplinary paradigms where scholars solve puzzles according to established frameworks (e.g., Abbott 2001; Knorr-Cetina 1999; Kuhn 1970; Mäkinen 2019). Moreover, many issues can arise related to facilitating, promoting, defining, and assessing interdisciplinary collaboration (Aldrich 2014; Lindvig and Hillersdal 2019). Scholars may face cognitive challenges, time pressure, and lack of support from their institutions (McBee and Leahey 2016). At the level of collaborative interactions, scholars' different styles of thought, standards, research traditions, techniques, and languages can be difficult to translate across disciplinary domains (Knorr-Cetina 1999; Kagan 2009; Mäkinen 2019). 
Despite reported controversies and debates around interdisciplinarity, interdisciplinary research centers have not disappeared. In fact, it seems that public and private investments in interdisciplinary research goals have only increased. Following in the footsteps of prior research on how universities restructure both research and teaching around interdisciplinarity (e.g., Padberg 2014; Crow and Dabars 2014, 2015), our study explores the ways in which interdisciplinary research centers facilitate collaboration across disciplinary boundaries. Focusing on what happens to knowledge production in interdisciplinary institutional contexts, some scholars have studied how several organizational factors (e.g., team size, shared building, leadership structure), taken together, promote or impede interdisciplinary collaboration (Hollingsworth and Hollingsworth 2000; Stokols et al. 2008a, b). This research has relied on literature reviews or quantitative data and focused on the extent to which organizational features can influence the amount of interdisciplinary collaboration or the number of research outputs. Taking a different perspective, the present study will address the question how collaborative arrangements shape experiences of interdisciplinary collaboration and culminations of interdisciplinary knowledge.

In order to capture scholars' experiences of distinct collaborative arrangements, we conducted three in-depth qualitative case studies on different interdisciplinary research centers. We refer to them as the Biotech Center, the Environmental Center, and the Premature Birth Center. We selected these case study organizations, because their mission was to conduct collaborative interdisciplinary science (see Calvert 2010), they were all located in the same university, and they operated across the fields of natural sciences, medicine, and, to some extent, social sciences. Our analysis of 53 interviews with active members of the interdisciplinary centers shows how the scholars saw 1) the center's mission, 2) physical architecture, and 3) leadership and task structure shaping collaborative behavior, research processes, and types of interdisciplinary knowledge.

The paper begins by locating our study in prior work on scholars' participation in and experiences of interdisciplinary collaboration. We then describe our data and analytical approach and introduce the case study organizations. The empirical sections focus on the interviewees' experiences of conducting interdisciplinary collaboration in each center's collaborative arrangement. The paper concludes with a discussion on the ways in which collaborative arrangements can pattern behavior and direct knowledge creation towards particular knowledge culminations.

\section{Interdisciplinary Collaboration, Centers, and Scholars}

As interdisciplinarity has gained prominence in academic institutions, sociologists of science and knowledge have become interested in understanding the nature of interdisciplinary collaboration and its role in academic knowledge production. Interdisciplinary collaboration has been studied using many approaches. Scholars have, for instance, analyzed publication data and citation patterns (Biancani et al. 2014; Dahlander and McFarland 2013; Rawlings and McFarland 2011; Hampton and Parker 2011), observed the day-to-day activities in research groups (Kaplan et al. 2016), and examined scholars' experiences of and thoughts 
on interdisciplinary collaboration (Lengwiler 2006; Strober 2011; Boix Mansilla et al. 2015).

Our study aligns closely with those studies that have examined interdisciplinarity from the perspective of scholars. Our focus is on understanding how scholars' participation in interdisciplinary collaboration is affected by the interdisciplinary research centers they are part of. While we acknowledge that epistemological aspects influence scholars' efforts to integrate different forms of knowledgewhich has been widely discussed in prior research (e.g., Knorr-Cetina 1999; Holland 2014) —we seek to explore the role of organizational arrangements in scholars' attempts to engage in interdisciplinary activities.

We are not the first to tackle this type of question. Some scholars have considered if particular features of the centers' organizational structures influence interdisciplinary collaboration. Stokols and colleagues reviewed literature from various fields and discussed how contextual factors may promote or impede interdisciplinary collaboration in science (Stokols et al. 2008a, b). They considered, for instance, how team size and social cohesiveness impacts collaboration. Based on quantitative data on interdisciplinary centers, Hollingsworth and Hollingsworth (2000) found that a shared location, small size, and distinctive leadership promoted successful discoveries.

Drawing on quantitative survey data, Boardman and Corley (2008) investigated how centers that are designed to coordinate scholars from disparate disciplines promote interdisciplinary collaboration. The authors selected center-level characteristics, such as the centers' ties to industry, the quantity of disciplines presented at the center, and the size of the centers. In turn, they measured scholars' collaborative behavior by the percentage of time they spent working with colleagues from varied disciplinary backgrounds. With this approach, the authors sought to capture how variation across centers' organizational features related to the composition of collaborative behavior.

While this research has established that there is a relationship between certain organizational features and the amount of interdisciplinary collaboration (e.g., Hollingsworth and Hollingsworth 2000; Stokols et al. 2008a, b; Boardman and Corley 2008), our qualitative case studies provide evidence on how collaborative arrangements shape scholars' experiences of interdisciplinarity and understandings of interdisciplinary knowledge culminations. By focusing on the "how," we do not look at what kind of organizational designs produce less or more knowledge products. Instead, our study brings attention to the conditions and processes that mediate collaborative arrangements and research outcomes - a topic highlighted by Leahey and Moody (2014). This allows us to identify variation in the types of knowledge that interdisciplinary scholars in different centers produce. Furthermore, we take an emic approach and delve deeper into those characteristics of the interdisciplinary research centers that our informants see as important.

Next, we present our data and analytical approach and then give a short description for each of the centers in our study. The analysis section is structured around the three characteristics of collaborative arrangements our interviewees highlighted: 1) mission of the center, 2) physical architecture, and 3) leadership and task structure. 


\section{Data and Analytical Approach}

Our study focuses on three interdisciplinary research centers-the Biotech Center, the Environmental Center, and the Premature Birth Center-operating across the fields of natural sciences, medicine, and, to some extent, social sciences. They were located in a research university in the United States, which is famous for supporting and valuing interdisciplinary science. The university's culture is entrepreneurial and innovative. Since the early 2000s, the university has strategically expanded and enhanced existing interdisciplinary centers but also provided support for the creation of new centers. In this sense, the university is not unique as such actions have been present in universities in both Europe and the United States (see, for example, Crow 2010; Marquardt and Wilhelmy 2014; Padberg 2014; Crow and Dabars 2014, 2015).

In analyzing how interdisciplinary scholars experience and engage with interdisciplinary research, we employ data based on field observations, organizational records, and semi-structured interviews. We observed the centers over the course of two years, collected records on faculty and students from university offices, recorded events and membership changes on the centers' websites, and acquired annual reports for each center every year. By drawing on these different types of data sources, we build three qualitative in-depth case studies (Yin 2008). Although our primary empirical focus is on the interview data, we interpreted them in relation to all the information we gathered from centers. Next, we describe how we selected our interviewees, the interview protocol, and the analysis of the data.

We conducted 53 interviews across the three centers over the course of two years. We identified interviewees based on recommendations from center directors, whom we interviewed first, and selections from the affiliated faculty lists on the centers' websites. Table 1 is a descriptive table of our interview corpus. While a large number of people whom we contacted agreed to be interviewed (81\% of everyone contacted), there were some who refused to participate due to their busy schedules. All the individuals we interviewed were active members of the centers. As is to be expected in the fields of natural sciences and medicine, the majority of our interviewees were men.

The interview protocol focused on the interviewees' careers and scholarly work in the context of their home departments and the interdisciplinary centers. We asked questions relating to their education and training, position in a disciplinary department, and participation in and membership to the interdisciplinary centers. Once

Table 1 Overview of Interview Data

\begin{tabular}{llcc}
\hline Center & $\begin{array}{l}\text { Total Inter- } \\
\text { viewees }\end{array}$ & Men & Women \\
\hline Biotech................ & 19 & 14 & 5 \\
Environmental......... & 19 & 13 & 6 \\
Premature Birth........ & 15 & 9 & 6 \\
Totals.................... & 53 & 36 & 17 \\
\hline
\end{tabular}

Response rate of $81 \%$ on requested interviews; Interview lengths ranged from 30-144 minutes (Avg.=70 min.) 
we had a sense of who these scholars were and what their research was like, we focused on how the researchers experienced centers as facilitators of interdisciplinary research. For our informants, interdisciplinary collaborations were research projects conducted with other members of the research center in an effort to "pool their experience, knowledge, and social skills with the objective of producing new knowledge, including knowledge as embedded in technology" (Bozeman and Boardman 2014: 2). By a collaborative arrangement, we refer to the organizational context that framed the interdisciplinary collaboration among two or more scholars from different backgrounds, affiliated with a given center, and seeking to create new knowledge together.

We used a collaborative and modified inductive approach to analyze the transcripts and arrive at a coding scheme (Glaser and Strauss 1967). The three authors shared the responsibility of interviewing members of the centers. After each interview, the interviewer had written a summary of the major themes discussed by the interviewee. We began the collaborative, analytical process by first reading through the interview summaries as a research team. Our discussions on the major themes present in the interviews facilitated the development of the first set of analytical codes. We did not conduct an open coding process on all of the transcripts, but relied on "open reading" of the interview summaries as a group (Strauss 1987).

As the main part of the interviews was to understand how scholars experienced centers as facilitators of interdisciplinary research, the first analytical codes highlighted characteristics such as the relationship between the scholar's work and the center, physical space, collaboration practices, and the roles of research collaborators. We then assessed the suitability of these initial codes and explored their dimensions in different centers by using the code scheme to analyze a set of full interview transcripts. After multiple team discussions and iterations, we arrived at a shared understanding of our analytical codes. The first and second author, then, coded all of the interview transcripts using ATLAS.ti, a software package for qualitative analysis. Disagreements on the applicable codes were solved during the research process through collaborative discussions.

\section{Overview of the Three Centers}

The idea of the Biotech Center germinated in the 1990s and its mission was to use interdisciplinary approaches for making new discoveries in biological systems that will benefit human health. The center's founders and subsequent directors recruited highly productive scientists who were interested in biology-related interdisciplinary work. The center filled with biologists, biomedical researchers, and medical clinicians, and a new breed of biology-related scholars in bioengineering, biophysics, bioinformatics, and biostatistics. The Biotech Center had a primary building (we refer to it as Bio Space), which provided open lab spaces for its affiliates. The building had both state-of-the-art technology, such as a forge for microfluidic chips and spectrometry equipment, and social spaces like a coffee shop and a gourmet cafeteria. 
The Environmental Center was founded in the early 2000s and its mission was to solve environmental problems. The center was an umbrella institute for seven smaller programs that recruited scholars on the basis of their interest in environmental issues. Researchers were recruited from earth science, education, and law, as well as from geology, marine ecology, and economics. The Center was housed in a building we refer to as ENV2. As a physical space, the building has some of the same characteristics as the Bio Space, like a coffee shop. Whereas Bio Space was entirely purposed for the Biotech Center, the ENV2 building was only partly purposed for the Environmental Center. Additionally, the lab spaces were located in the basement of the building, separate from faculty offices. In the following analysis, we reflect on how these differences in the layout matter for collaborative interactions.

The Premature Birth Center was founded in the early 2000s through a partnership between a School of Medicine and a non-profit foundation. The mission of the center was to study and prevent premature birth. The center's organizational plan consisted of four scientific inquiry areas that had a methodological focus, and whose participants come from different disciplines. The inquiry areas, their principal investigators, and other members were recruited by the center directors from the university and local industry for the expertise they could leverage toward solving premature birth. They came from obstetrics-gynecology, pediatrics, neonatology, epidemiology, infectious diseases, genetics, bioinformatics, and social demography. Space-wise, the Premature Birth Center did not have its own building. The members were spread across the campus and saw each other weekly: once a week the center held a series of meetings and members knew to schedule and attend accordingly.

\section{Collaborative Arrangements and Scholars' Behavior}

In our observations of the centers and analysis of the interview data, we discovered three characteristics of collaborative arrangements that the interviewees described as significant for their interdisciplinary research efforts. Next, we show how 1) center's research mission, 2) physical architecture, and 3) leadership and task structure shaped scholars' participation in interdisciplinary collaboration.

\section{Centers, Scholars, and Goal Alignment}

Rhoten (2005) has criticized interdisciplinary centers for organizing their research efforts around catchall themes rather than specific problems. In her view, the latter approach would be better for meaningful outcomes. Yet, it has been noted that how a problem is defined determines which solutions are seen as relevant (Getzels 1975). A particular definition of a shared research problem may impede the creation of innovative discoveries, which is typically one of the main goals of interdisciplinary research centers.

In relation to this tension, our interviewees repeatedly reflected on the alignment between their own research interests and their center's mission. When an interdisciplinary center recruited scholars whose research goals aligned closely 
with the mission of the center, the interviewees expressed commitment to the shared effort. This motivated them to engage in research projects with other members of the center. However, when the interviewees expressed confusion over how their work related to the center, they were less excited about the shared goals and less motivated to participate.

\section{The Biotech Center}

The Biotech Center grew out of a grass-roots movement of faculty who believed interdisciplinary research was the means to advance biological research and the study of human health. Thus, they sought to adopt interdisciplinary research approach as a means to scientific innovation in biology. The center's directors recruited highly-productive scientists-biologists, medical clinicians, and new breeds of scholars in bioengineering, biophysics, bioinformatics, and biostatistics - who had shown a track record of engaging in biology-related interdisciplinary collaboration. Notably, the scholars we interviewed felt that their research interests aligned with the center's overall mission. One scientist described his recruitment into the Biotech Center:

I didn't want to do it [the Biotech Center] unless it looked like this was better. Really, it looked way better, because they had taken care of a lot of the hassle of interdisciplinarity for me. Like...me having to get two tenure committees. They just figured a bunch of that stuff out. Felt very comfortable. Much better fit than most of these other places because of that. There's just like a clear culture. I can imagine that a lot of people like me came. [ID-9]

By making scientific collaboration across disciplinary boundaries easier to perform, the Biotech Center facilitated the recruitment of scholars whose scholarly interests aligned with the center's mission-even among somewhat skeptical recruits like the scholar voicing the previous quotation. Though scholars pursued interdisciplinary collaborations prior to their involvement with the Biotech Center, they argued that their experiences in the center amplified their commitment to the interdisciplinary approach. One scientist, in particular, described the attitude well:

I was collaborating with engineers and technologists, trying to develop new techniques in developmental biology. It was really important to have that mix of expertise...[I] had exposure to interdisciplinary science before that, but [the Biotech Center] was really where I learned about the value of these interdisciplinary labs... The lab couldn't run if you just required people from one background...It would be almost impossible. [ID-6]

Scientists felt that the Biotech Center "is our home, and we are quite happy with the way everything is working" [ID-29] and that "the themes that are embodied in the Biotech Center" are "themes that, experimentally, I have been dealing with my entire career" [ID-52]. 


\section{The Environmental Center}

The scholars at the Environmental Center similarly described their research interests aligning with the center's research mission. This was not surprising given that the center recruited scholars on the basis of their interest in environmental issues. 11 of our 19 interviewees described their prior work as environmental, and another four said that while their prior research was in basic science, shifting interests to environmental issues led them to the Environmental Center. Sentiments such as "I was always motivated by environmental challenges" [ID-37] and "I have always been propelled to do the work that I do... which is environment and conservation" [ID2] were common among these scholars although they were trained in varied fields ranging from law to engineering to geology to medicine.

Scholars' alignment with the center's focus on environmental problems shaped their commitment to the interdisciplinary research approach. The scholars at the Environmental Center viewed an interdisciplinary approach as an essential means to studying environmental problems. One social scientist said that "I could never have done the [research] that I did in this area without showing it to a natural scientist" [ID-28], revealing his belief in the necessity of interdisciplinary collaboration for his work. Another researcher described his growing investment in interdisciplinary research: "I was beginning to have this realization that, because I do ecology and environmental science, if I wanted to solve problems in the real world, I needed to know a lot more about the human dimensions and the institutions and the laws" [ID-10]. Another saw environmental topics as "inherently interdisciplinary" to the point that thinking about them through only a single discipline is futile: "I would say climate change is an inherently interdisciplinary thing...There are elements of climate change that you cannot even start to talk about [without multiple disciplines]" [ID-18].

For scholars, strong alignment with the interdisciplinary goals of the Environmental Center accompanied a belief that environmental problems could not be solved with knowledge coming out of formal, disciplinary science departments. "More science did not seem to be making more progress" [ID-10] said one researcher about a disciplinary approach; another said that "if you can say what discipline you are in, you are probably doing something old" [ID-16]. These scholars also distanced themselves from disciplinary scholars who failed to solve problems in the "real world," saying that "The people who were stuck in their disciplines and arguing that we should not get into the real world and help solve problems, I think, have been left in the dust" [ID-10]. These disparaging remarks about disciplinary work revealed scholars' perceptions of the importance of engaging in interdisciplinary efforts, which they perceived as progressive and addressing real problems.

\section{The Premature Birth Center}

In comparison, in the Premature Birth Center, researchers repeatedly noted that their own research interests were not closely aligned with the mission of the 
center. The center directors had recruited bioinformaticians, immunologists, geneticists, and clinicians because they had expertise in a distinct line of research that could help diagnose a facet of the problem of premature birth. Many had not researched the topic before, and coming from diverse backgrounds, scholars had difficulty identifying with the topic of premature birth and each other. One of the center's directors noted, "The center collaborators, they have not all worked together. They worked in pieces, parts, and different threads" [ID-53]. This was a challenge for creating a close-knit intellectual community with aligned research goals. One scientist said that when he tried to participate in a project and contribute his expertise, he found it difficult to both clearly state his knowledge and feel valued by others:

I feel like what I bring to the table is an understanding of...the clinical problem of premature birth over the years. For better or worse, the [other] people...have no experience in that. These are guys who have made a living studying [something very different]...I wasn't able to explain what I felt like were the clinical correlates, or...they didn't feel like that was important to hear them. [ID-42]

At the Premature Birth Center, clinician investigators and scientists had a hard time connecting their different forms of expertise. Sensing a lack of respect from his collaborators, this clinician investigator "lost interest in [the collaboration]...I really felt as though I wasn't able to contribute very much" [ID-42]. One scientist felt "initially [that] it didn't seem like it would be a group where I would have a fit, but then over time, some of the issues that they are looking at are things that I have thought about or done some research in" [ID-35]. With time, this scientist's sense of alignment with the group grew, based on finding common issues. However, for many of his colleagues, this was not the case, and some scientists and clinician investigators left the center to return to specialized research pursuits.

Compared to members of the Biotech Center and the Environmental Center, participants of the Premature Birth Center had doubts about the usefulness of interdisciplinary research approach in the context of premature birth. Asked if scholars were initially skeptical about the center's mission, one center director responded: "I think people are still skeptical, so absolutely, yes" [ID-53]. One scholar felt skeptical about successfully mixing fields of expertise, a sentiment very different from what we saw in the Biotech and the Environmental Centers:

There's a lot of B.S. in this, right? There are people in here that are put in here for grantsmanship purposes, but... will probably never really contribute in some sort of meaningful way. It's not because they are not engaged or excellent scientists in their own fields, but what spurs this sort of interdisciplinary study is that you have a common interest. [ID-3]

This scientist saw the emphasis on crossing disciplinary boundaries as superficial in part because they lack aligned interests.

The Premature Birth Center was, however, willing to work towards increasing the alignment between scholars' expertise and the center's broader mission. One 
of the center directors sought to educate the participating scholars, saying "the challenge that I see right now is...bringing everybody up, figuring out how to get everybody suitably informed, just sort of at a baseline level about premature birth" [ID-53]. This could be difficult, as she went on to say that, "We don't know what it is that people need to know, because the range of knowledge and skill is so great" [ID-53]. Other directors argued that the center needed to foster alignment between the topic of premature birth and scholars' prior interests. As one of them explained while talking about another scholar at the center, "She doesn't know very much about premature birth but she knows all about [technologies that can be used to study the problem]... How do you even engage her so that she will say, 'Well geez, that's a lot like [my specialty]. Solving premature birth is a lot like solving [a problem in my field], isn't it?"' [ID-22]. By these educational means, the directors of the Premature Birth Center were trying to foster alignment between the scholars and the center.

To summarize, the Biotech and the Environmental Centers exemplified how an alignment between the center's mission and scholar's research interests occurred in conjunction with commitment to and belief in interdisciplinary research approach. Scholars joined on the basis of their own research interests, found a community of like-minded others, and committed to the shared effort. Furthermore, in both cases, scholars saw interdisciplinary research approach as the best way to advance science in their fields. In the Premature Birth Center, scholars' interests were not aligned with the center's mission. As such, scholars expressed mistrust of the benefits of interdisciplinary research approach.

\section{Significance of Physical Architecture}

Our informants highlighted the role of the physical space when discussing their participation in interdisciplinary research projects. Indeed, built environments and physical layouts of workplaces have been shown to shape possibilities for interaction and collaboration (e.g., Davis 1984; Allen 2007; Kabo et al. 2014). In our study, physical spaces related to how scholars were able to interact with each other. Interaction was important, because it created opportunities for discussing research interests and ideas for shared projects. Our interviewees described, in particular, how physical architecture facilitated informal, chance encounters that were meaningful for promoting interdisciplinary collaboration. Kabo et al. (2014) similarly found that when researchers traverse paths with greater overlap at the workplace, their propensity to form new collaborations increases. These shared paths can lead to, for instance, elevators and restrooms, or as in our case, a coffee shop.

To understand how different physical and social spaces can pattern collaborative behavior, we contrast the Bio Space, the Biotech Center's dedicated building, with the Environmental Center's primary building ENV2. We also discuss how the Premature Birth Center, the only center without its own building, relied on meetings to promote interactions among its members. 


\section{The Biotech Center-Bio Space Building}

More than half of the Biotech Center interviewees described the Bio Space as transforming their interactions with other scientists and, as a result, their collaborative behavior; as one scholar said, "the Bio Space building, more than the Biotech Center, has done a lot for me" [ID-7]. The scientists attributed the building's impact to its open floor plan: faculty offices were placed in the center of their labs and each lab was adjacent to other labs. "At the Bio Space, you have all of these interactions that go on in these open wet lab spaces" [ID-6] one scientist described. Another one said:

What I really like about the Bio Space is that it's so open. Some people hate it. I love it. I love having my office right here where everyone can see me, mostly where I can see everyone else...I actually now feel claustrophobic in other labs. [ID-9]

One scholar even acknowledged that "moving into the Bio Space correlated with me getting tenure" and went on to explain how the shared physical space transformed his work:

I went from being in a building where I was isolated, focused on my own $\mathrm{CV}$, my own professional success. Then I was thrown here. I had a much bigger swath of the university to interact with...I thought that over the next few years my research interests would evolve. I found that in the first few months I got involved in major, major grants that I never would have been involved with if I hadn't moved into the building. [ID-1]

Relocation into the Bio Space changed the nature of this scholar's work and led him to scale up his work from self-focused, CV-oriented work to "major, major grants." As further evidence for the importance of the Bio Space and the interactive behavior it fostered, one scholar expressed concern over a potential move away from the campus. His concern showed how important the patterns of interaction in the Bio Space were for the scientists experiencing them:

I have become more appreciative of the behavioral influence that close proximity and geography has on people. It has been critical for us that if I have collaborators on the main campus, we go meet at the coffee shop at the Bio Space. That's a common meeting place for us because it is equidistant between their office on main campus and here. It's a few-minute walk, and I'm concerned about moving off campus. I'm hoping it's a temporary move. [ID-36]

Referenced in the prior statement, there was a particular aspect in the Biotech Center's physical architecture — a coffee shop—-that was repeatedly described as facilitating informal interactions, which were important for initiating new collaborations. Half of the interviewees characterized the coffee shop in the Bio Space building as a prime location for jumpstarting research collaborations. For the sake of comparison, none of the interviewees from the other centers mentioned a 
similar meeting place. Not even members of the Environmental Center, although their building had a similar coffee shop. Reflecting upon the coffee shop, a member of the Biotech Center noted that "the coffee shop actually makes a big difference...It makes a big difference because you see everybody up there" [ID-9], and another researcher whose lab was near the coffee shop said that "People are coming by the coffee shop all the time, so I am well placed for just bumping into people" [ID-25]. Our informants attributed the creation of interdisciplinary projects to chance encounters at the coffee shop. One scientist said that a postdoc is "working on a project that just arose from a random collision in the Bio Space building" [ID-6] and another doubted whether his interdisciplinary collaborations with medical clinicians would exist without run-ins at the coffee shop:

I'm not sure all those things I do with the clinicians would happen if I was on the other side of campus somewhere and it wasn't so easy to pop by and see them or run into them at the coffee shop every morning. [ID-48]

The Bio Space building's coffee shop is "the kind of place where I think people expect to...talk to other people about what's going on" [ID-25] with their work. The scholars took advantage of informal encounters at the coffee shop to learn from each other and foster interdisciplinary collaboration.

\section{The Environmental Center-ENV2}

While the Environmental Center also had a primary building, ENV2, our interviewees did not describe its impact in similarly positive terms. Although the building had a coffee shop, it did not facilitate chance encounters the same way as the coffee shop in the Bio Space building. Overall, ENV2's design was less open as compared to what we observed in the Bio Space. Unlike the half of the Biotech Center interviewees who talked about the Bio Space, only a couple interviewees at the Environmental Center talked about ENV2, and those comments differed greatly from those of the Biotech scholars. One scholar explained:

[ENV2] is so big that I'm not sure that putting everybody in one building makes a major difference. I think instead it's the way in which areas of the building may be organized. When we created the building, we tried to organize it so that it was organized by subject area rather than by discipline. So you have an area with oceans, an area of fresh water. To the degree that has worked in a building so large...I'm not quite sure that I have seen enough of it to know... but it is interesting that even though we are in one building, I feel as if half the people are in a totally different universe. [ID-58]

This scholar recognized that the simple co-location of scholars in one building was not enough for increased contact, but that the physical layout and the movement of scholars in this space actually mattered. The scholar had noticed, for instance, that organizing members topically in the building connected some researchers but kept others "in a totally different universe." The layout of a physical space can strengthen intellectual divides. 
While the Bio Space was modeled after biology's traditional open labs, ENV2 was more closely related to civil and environmental engineering spaces, in which researchers have separate, locked spaces for themselves and their research assistants. One researcher complained about ENV2, saying, "At the macro level it could have been designed with the faculty in clusters that had shared offices and suites where we see each other coming and going" [ID-32]. The scholar went on to complain that frosted glass, limited stairwells, and long hallways led to infrequent interactions that could have sparked collaborations. Kabo et al. (2014) showed it is not that stairwells and hallways always limit chance encounters. What matters is the extent to which scholars are likely to run into each other in these spaces while moving from, for instance, their office to the restroom or a coffee shop. Based on our informants' accounts, ENV2 building's layout and how scholars were placed in it did not promote these chance encounters.

Instead, we found that informal interactions among the members of the Environmental Center happened outside of the work context as many of the members had friendly relations. This pattern went back to the founder scientists who had worked together as friends and imported their interdisciplinary collaborations into the center. One scholar said, "I think there's very much a sense of the [Environmental Center] being a family" [ID-2], a sentiment that was not expressed among members of the other two centers. These personal relationships at the Environmental Center went hand in hand with research collaboration:

It was really fun. We made good friendships. We would have dinner together a lot on the outside. We became godparents of each other's kids, and we really, really - [we had] wonderful kinds of collaborations. [ID-41]

Although the shared building of the Environmental Center did not generate opportunities for contact the same way that the Bio Space did, the informal networks, especially in the center's early days, supported collaborative interactions.

\section{The Premature Birth Center-Meetings}

Collaborative interactions among scholars at the Premature Birth Center were organized in formal settings, primarily through weekly meetings. In its initial form, the center organized monthly meetings for each of the four scientific inquiry areas. Perhaps because of these area-specific meetings, the first research projects tended to lie within the principal investigators' individual labs rather than across them. Consequently, the first research efforts were more disciplinary than interdisciplinary. As one of the center directors explained:

When we first designed the architecture of the center we saw these areas of inquiry as being areas that would have mixing within and between them. What essentially happened was that they became their own siloes. [ID-53]

The interviewee went on to explain how the center sought to overcome the siloes by rearranging its meeting structure in order to promote collaborative interactions 
across two distinct data groups, namely, dry and wet lab science (see Penders et al. 2008):

Now what we're going to try to do...is to create two groups that are still bridged together by lots of people. There is one that is dry lab based, like that data resource group [a group that compiles big data on premature birth from various sources], and the other one that is more biologically based [a group focused on the analysis of human specimens], that is more bench-like in terms of its experimental designs. [ID-53]

By redesigning the group and meeting structure, the directors hoped to create a better forum for collaborative interactions and knowledge mixing between different analytical approaches. As one of the directors envisioned: "We will have a large, more amorphous group of people dealing with data of different sorts and assembling teams which reflect the different questions that are being asked and the different work products that are being proposed" [ID-57].

In seeing how physical structures can enhance collaboration, we highlighted the Biotech Center. According to our informants, the Bio Space was a physical facility that increased unplanned, casual interactions. To understand how differently physical and social spaces can foster collaboration, we contrasted the Bio Space with the Environmental Center's primary building ENV2, which the interviewees did not see as supporting informal interactions. The Premature Birth Center, the only center without its own building, relied on meetings to promote interactions among its members.

\section{Leadership and Task Structure}

As the size of scientific teams has been increasing, teams will face new challenges related to division of labor and coordination of project participants (Wuchty et al. 2007; Cummings and Kiesler 2007). Relatedly, our interviewees reflected on how leadership and task structure in the context of the different centers affected scholarly autonomy and responsibility on research projects. Depending on the characteristics of the center's leadership and task structure, researchers were included and assigned work roles on interdisciplinary research projects in different ways. Whether they were central or peripheral in the collaboration shaped how the interdisciplinary research process influenced them and their future research efforts.

\section{The Biotech Center}

In the Biotech Center, research projects were team science efforts, and graduate students and postdoctoral researchers were frequently allowed to take the lead on research papers. Additionally, graduate students and postdoctoral researchers were encouraged to work in multiple research labs (especially those in other fields) throughout their entire term of study in the Biotech Center. That norm, coupled with the Biotech Center's open floor plan, served to create an exchange of graduate 
students and postdoctoral researchers across labs, which showed also in research publications.

In most instances, graduate students and postdoctoral researchers took responsibility for bringing together collaborators and expertise across disparate research groups. One scientist described the postdoctoral researchers as "the main leaders of research" [ID-51]; another explained that "the reason that the [research] process is different is that it's led by a postdoc" [ID-6]; and a third said that "We had a student, Mike, who really was the key driver of the project" [ID-9]. One of these faculty members, who had been trained in molecular and cell biology, talked about a specific project led by a graduate student:

[My student] backed up to something that was simpler and more physical, and so you end up with a paper that actually looks a lot like a physics paper in the end. It started out as something that looked more like a biology project. In that case, really, the path that he has taken has been much more self-guided. [ID-6]

As the student took the lead in the collaboration, he combined approaches from biology and physics and created a project that was self-guided and different from his typical work.

Because students and postdocs led collaborations, they often became hybrid scientists whose expertise contained skills learned from multiple faculty labs. The faculty researchers recognized the transformative impact this task structure had on students, one of them noted:

What was very different about this collaboration was that in most collaborations, people stay in their home space, and they get together once a week, once a month, and have a joint session to talk about what's happening in the two spaces and how they can combine this into a paper. What we did was totally different, because our students and postdocs who were used to soaking up stuff-more than us old guys are-lived for significant amounts of time in a different environment. That transformed those folks. [ID-55]

The faculty recognized that the graduate and postdoctoral researcher based collaborative set-up was unique and impactful, describing it as "absolutely invaluable" and "a tremendous opportunity" not just for the students but also for their own work [ID-36].

\section{The Environmental Center}

In the Environmental Center, the task structure of research projects put the responsibility for knowledge integration into the hands of faculty members. 14 of the 19 interviewees described their research projects as being dependent upon collaboration with faculty members from multiple disciplines. Typically, collaborators worked together on a single project that blended their different disciplinary frameworks together into a holistic analysis of an environmental topic. Differently from the Biotech Center, the faculty at the Environmental Center seemed to move across papers rather than physical locations, such as labs. 
One scholar from the field of hydrology described an interdisciplinary project he was involved in: "That is not a study that I would ever have done on my own or with a $\mathrm{PhD}$ student to advance the field of hydrology. The advancement in hydrology was trivial. What was important was using the hydrology in a way that was of benefit to a soil chemist" [ID-26]. In this project, the expertise of one faculty-the hydrologist-was used to enhance the understanding of an environmental issue in another area, soil chemistry, as is typical in a research project in the Environmental Center. As one scholar noted about another project: "It's where you're really spanning a lot of disciplines. You're just trying to give more of a synthetic view that would engage ideally a lot of different people" [ID-12].

With regards to interdisciplinary knowledge integration, the scholars emphasized that while each collaborator was literate in the work that others contributed, it was rare that a single scientist could perform all parts of a project:

For me, it's a real interdisciplinary product because all the people that came to the table came mostly with a very narrow interest and there was this hope or expectation that all these components would lead to a big picture. [ID-30]

The interviewee described an interdisciplinary project where faculty from different disciplines came together, but each brought his own expertise as a component of the "big picture." The faculty members rarely felt they understood each other's work well enough to conduct the project alone. One scholar described a particular collaboration and said: "If you look at this paper or any other ones that we have published together, I couldn't sit down and do everything in it and he couldn't sit down and do everything in it" [ID-16].

Yet, the Environmental Center faculty said that their experiences of interdisciplinary collaboration transformed how they understood and framed environmental topics. Half of the interviewees specifically described a transformed understanding and framing of a topic because of their participation in interdisciplinary collaborations. These two scientists, for example, emphasized how their selection of research questions had changed:

I think very differently now about solutions to climate change problems as a result of having been around economists and policy people... That's absolutely had an impact on how I think about the science I do. It certainly has an impact on how I select problems. [ID-18]

I never had thought about history in the context of environmental problems. The [Environmental Center seed grant] project opened my eyes to how much historians bring to the table...It has been a larger shift in terms of how I view problems in general, I don't go in just thinking chemistry, physics, or biology any more. I take a much more holistic approach to thinking about what is the problem that we're really talking about here? What are the questions that we want to go after? And what are the large-scale pieces that we need to pull in to do that? [ID-20]

Therefore, although for the scholars at the Environmental Center we did not see a similar kind of individual level transformation as we did among the Biotech Center's 
graduate students and postdoctoral researchers, it was evident that interdisciplinary collaborations had led to the creation of new, holistic framings on environmental topics. In turn, these new framings shifted the scholars' approaches on their future research.

\section{The Premature Birth Center}

Two characteristics of the Premature Birth Center differentiated it from the other two centers, in particular, when we considered their leadership and task structures. First, while the other centers had broad topical foci that allowed faculty to pursue a range of projects (human health and environment), the Premature Birth Center had a very specific goal: to understand and reduce the rate of premature birth. Second, the Premature Birth Center was the only center in our study that had to show continuous progress to a funder. Connected to these two characteristics, our interviewees talked about leadership and task structure where the center directors were the primary actors in interdisciplinary collaboration. The directors who were senior faculty were very hands-on: they actively oversaw research projects and synthesized findings to make sure that there was constant, on-topic progress (Mäkinen 2018).

In the center's initial stages, pressure from the funder led participants to work individually within their own labs and disciplines because this was the quickest route to results. One director saw this as a natural response: "It's easier to fall back into a traditional mold and do studies that look a lot like all the studies we've done before in our careers, and so it gives us the semblance of the perception of progress, of success because we're publishing" [ID-59]. Half of the interviewed scientists said that although the problem focus of their work had changed after joining the Premature Birth Center, their interdisciplinary projects looked similar to their disciplinary work. One scientist noted: "To tell you the truth, from my disciplinary standpoint, [my work in the center] is not that much different than most of the other things I do" [ID-53].

To promote interdisciplinary collaboration, the center directors took on boundary-spanning roles and acted as knowledge brokers (Tushman 1977; Burt 2004; Mäkinen 2018). Boundary individuals in heterogeneous teams need to have the knowledge of the different expertise and skills present in the organization and the ability to activate them (Allen 1984). The center directors succeeded in collecting findings from the constituent scientists and combined their knowledge in interdisciplinary publications. One director described this brokering process, saying "I go from having conversations about...genetics and how to measure lipids...to talking to a psychology professor [about]....an intervention trial" [ID-53]. From these disparate sources, the directors pulled the best and most relevant findings and synthesized them into publications, which was important for the funder. One director noted: "The funding agency and reviewers need to be fed. They need to be fed and we need to give them sustenance, and that means publications" [ID-59]. Specifically, publications that demonstrated interdisciplinary knowledge creation focused on premature birth. 
In this leadership and task structure, the center directors became familiar with all parts of the project, but the compositional scientists did not. There was often discomfort among the scientists around authorship, as they imagined being challenged on portions of the theory or methods that they did not perform. Through discussions about authorship, one center director sought to make the scientists more comfortable with current projects and to prepare them for future collaborations:

[A scientist says,] "I can't be an author because I just didn't do enough," you say, "What didn't you do? You did this, this, and this." They say, "Well, I don't understand this." We say, "Okay, let's make sure you understand it, then, because you made contributions which you may not appreciate, but you did this, this, and this with the paper, so you should be an author." Then you teach them, and then they are more comfortable. Then the next time, they are even more comfortable, and so forth and so on...We actually do things like that now, more consciously. [ID-57]

This description highlighted the active role of the center directors in producing a paper where knowledge across fields of expertise was combined. The directors recruited scientists and their contributions into a paper and brokered authorship agreements with them. While "next time" the scientists might submit their work to the collective effort and accept authorship with less guidance, for now, the center directors were active and conscious brokers in interdisciplinary collaborations. They noted that it "requires a lot of energy to assemble everybody...But when you have people in the right leadership who convey that, I think we can pull it off" [ID-53].

This section demonstrated how the centers' leadership and task structure shaped the researchers' experiences of interdisciplinary collaboration and how the collaborations affected the researchers' future work. In the Biotech Center, students were directly involved in the combination of knowledge across different disciplines and were transformed by these experiences. In the Environmental Center, faculty members collaborated with each other, which transformed their perspective on environmental problems, but did not necessarily change their individual skillsets. In the Premature Birth Center, the center directors took a top-down approach in their promotion of interdisciplinary collaboration. They themselves became knowledgeable in every aspect of the overall research effort.

\section{Discussion: Collaborative Arrangements and Interdisciplinary Knowledge Culminations}

In this study, we examined how different features of interdisciplinary research centers' collaborative arrangements shaped scholars' experiences of interdisciplinary collaboration. Next, we summarize the key findings and discuss the variation we found in the centers' interdisciplinary knowledge culminations.

Prior research has examined the topic of organizational arrangements and interdisciplinary knowledge outcomes by analyzing quantitative data on organizational characteristics and their relationship to time spent collaborating with varied scholars or number of interdisciplinary discoveries (e.g., Hollingsworth and Hollingsworth 
2000; Boardman and Corley 2008). While this work sheds light on the extent to which centers' organizational arrangements influence knowledge production, what is missing is an understanding of how particular features of these collaborative arrangements condition the behavior of individual scholars and the styles of interdisciplinary knowledge they create.

Our study addressed this research gap by examining which features of the centers' collaborative arrangements interdisciplinary scholars saw influencing their work and how. Our study was centered on the experiences of our informants and, differently from prior research (Hollingsworth and Hollingsworth 2000; Stokols et al. 2008a, b; Boardman and Corley 2008), we did not preselect characteristics of collaborative arrangements or predetermine what counts as an interdisciplinary collaboration for our informants.

Three features - the center's mission, physical architecture, and leadership and task structure-were described as patterning collaborative behavior. We first discussed how the alignment between the center's mission and the researcher's own interests shaped the extent to which the researcher saw meaning in interdisciplinary research and felt committed to the center's overall effort. Second, we demonstrated how the physical architecture shaped how researchers were able to casually interact and exchange ideas with other scholars. Finally, we showed how the leadership and task structure were seen as influencing the depth of knowledge integration in the core individuals as well as their willingness to engage in interdisciplinary collaboration in their future work.

Understanding the nuances in the described experiences allows us to move beyond identifying associations between interdisciplinary research centers' organizational features and amount of knowledge produced (Hollingsworth and Hollingsworth 2000; Stokols et al. 2008a, b; Boardman and Corley 2008). A case in point, findings from a quantitative study by Hollingsworth and Hollingsworth (2000) suggested that co-location of researchers in one building increases interdisciplinary knowledge production. Our study showed, however, that the question of co-location and physical architecture is much more complex. The design and layout of a building shape how researchers move around, run into each other, and engage in collaborative interactions. Moreover, considering the different features of collaborative arrangements together, how scholars associate with the mission of the center, move around in a physical space, and divide work tasks are multifaceted and interconnected issues that shape knowledge production in complex ways, not only in terms of "more" or "less" knowledge produced.

We argue that how scholars experience different features of collaborative arrangements can partly explain the variation in the resultant interdisciplinary knowledge. We explain how in each center the three previously discussed features of collaborative arrangements emerged in different degrees and combinations, which then led to unique interdisciplinary knowledge culminations (see Table 2). We provide an example of a typical knowledge outcome for each center and discuss the extent to which this knowledge outcome is influenced by the center's disciplinary and topical foci.

First, the Biotech Center's collaborative arrangement facilitated interdisciplinary team science where new research projects seemed to crop up with ease as scholars 
Table 2 Collaborative Arrangements and Interdisciplinary Culminations

\begin{tabular}{|c|c|c|c|c|}
\hline \multirow[b]{2}{*}{ Center } & \multicolumn{3}{|c|}{ Features of Collaborative Arrangements } & \multirow[b]{2}{*}{$\begin{array}{l}\text { Interdiscipli- } \\
\text { nary Culmina- } \\
\text { tion }\end{array}$} \\
\hline & Goal Alignment & Physical Architecture & $\begin{array}{l}\text { Leadership and } \\
\text { Task Structure }\end{array}$ & \\
\hline Biotech & High & Frequent and Collegial Interaction & Student-Led & Product \\
\hline Environmental & High & $\begin{array}{l}\text { Frequent and Friendly Interaction } \\
\text { Outside Work }\end{array}$ & Faculty-Led & Framing \\
\hline Premature Birth & Low & Frequent and Formal Interaction & Director-Led & Brokerage \\
\hline
\end{tabular}

identified with the mission, interacted frequently and collegially, and exchanged students across labs resulting in new health applications. We find that these features and influences of the Biotech Center's collaborative arrangement led to interdisciplinary knowledge synthesis focused on products. The easiness in this interdisciplinary knowledge creation process relates to the scholars' prior interdisciplinary work and its alignment with the center's mission. Interdisciplinarity was not foreign to the researchers as team science and the creation of health technologies have become the new norm in the biosciences (McCarthy 2004). One scientist described a project that he would "call a [Biotech] one for sure" that demonstrates the kinds of translational products the scholars were able produce:

My student went to my collaborator's lab and...also took a course from my collaborator. My collaborator had never done a human experiment. He had never really done anything directly medical, but...now he's all over this. We've now had three joint students together, and we're starting a company together. Now we have one of these gadgets that - this was like a $\$ 500,000$ table-top microscope that [patients] had to crawl under and get poked, and I turned it into something... you just fold in your hand. [ID-14]

These scientists, in collaboration with shared graduate students, combined their varied expertise, did something they had "never really done," and created a new, marketable product that improved patient care by reducing the size and invasiveness of a procedure.

Second, in the context of the Environmental Center's collaborative arrangement, we found that the faculty felt committed to the center's mission, interacted frequently outside work, and coauthored papers together. The Environmental Center was home to researchers from the social sciences, professional schools, and hard and natural sciences, a much wider range of researchers than what we saw in the Biotech Center. This difference might explain why researchers felt they could not quite understand each other's contributions on shared interdisciplinary projects. Yet, the scholars' commitment to environmental questions and interdisciplinary research approach, combined with their informal networks, facilitated the creation of interdisciplinary culminations around problem framings. One scholar described a project that demonstrates this well: "[The project] was aiming to set out a framework to motivate research on the part of many other groups...It's where you're really spanning a lot 
of disciplines. You're just trying to give more of a synthetic view that would engage ideally a lot of different people" [ID-12]. Through synthesizing framings from different disciplines, the project introduced an environmental topic to new audiences expanding the topic's exposure.

Third, the collaborative arrangement of the Premature Birth Center was one where researchers did not immediately connect with the research problem, their interactions took place in regularly organized formal meetings, and the center directors acted as the intermediaries on projects. In the Premature Birth Center, members included medical practitioners and scientists from different fields, who relied on different analytical approaches, both wet and dry lab science (Penders et al. 2008). Like in the Environmental Center, there was a wide range of disciplinary and epistemological boundaries to cross in addition to the fact that the problem of premature birth was new to many of the researchers. As a result, interdisciplinary collaborations among different faculty and their students and postdoctoral researchers did not emerge organically. The Premature Birth Center's research efforts were managed by the directors, who put together interdisciplinary projects like puzzles: they were knowledgeable of every research effort in the center and could combine the expertise of varied scholars to create interdisciplinary projects (Mäkinen 2018). The center's interdisciplinary culminations resembled brokerage. The directors brokered and translated knowledge among different scientists, as one director described: "I said [to a new scientist], 'Well, then, tell me yourself, in your own words, in about a paragraph what you do.' I will take that and I will then massage that in a way that begins to make sense to other people. I will translate what he is doing into their worlds" [ID-57].

While our study is not meant to provide a recipe for manufacturing interdisciplinary collaboration in all universities, it is worthwhile to reflect on what can be learned from these cases of interdisciplinary collaboration. We suspect that once the paths towards particular interdisciplinary culminations become established, changing them requires rethinking the organization of collaborative arrangements. For the Biotech Center, this is not a problem as the center has been achieving its goals: translational discoveries that can benefit human health.

The Environmental Center and the Premature Birth Center, however, face challenges as with their current collaborative arrangements and interdisciplinary culminations they risk maintaining their interdisciplinary research activities over time. The Environmental Center benefitted from the longtime friendly networks among its faculty members. The question is to what extent will new scholars be able to integrate the preexisting collaborative networks? There is a risk that the advantage of the informal relations will disappear over time as new members join the center. At the same time, it is possible that new scholars' genuine interest in and commitment to the interdisciplinary study of environmental problems would be enough to make them feel as if they belong to the community.

In the Premature Birth Center, the center directors, who were skillful brokers, played a critical role in the creation of interdisciplinary projects (Mäkinen 2018). Yet, it is difficult to imagine how the center could maintain interdisciplinary activities if or when the directors were forced to step down. In his study on interdisciplinary centers, Lengwiler (2006) discovered how important, but also risky, the role of 
a charismatic leader can be. When a charismatic leader is absent, it is possible that interdisciplinary cooperation loses its integrating factor and falls apart. Interdisciplinary collaboration cannot be dependent on a small number of individuals at the top of the organization; it needs to emerge throughout the organization.

As interdisciplinary framing and brokerage do not fully correspond with the missions of the Environmental and the Premature Birth Center, the question is how they can transform their collaborative arrangements so as to achieve the hoped-for interdisciplinary culminations. For the Premature Birth Center, this could mean providing opportunities for education on the shared problem and increasing informal interaction in order to better motivate and include researchers on interdisciplinary projects. In turn, for the Environmental Center, this could mean exchanging junior researchers across labs in an effort to advance knowledge integration beyond framing of environmental problems. Indeed, interdisciplinary research centers require careful planning: they need to have a clear sense of the mission, hoped-for outcomes, and work processes, and then plan the collaborative arrangements in particular ways so they activate the set of available, interested individuals in the desired directions.

Acknowledgments This article is based on a research project that was generously funded by the Office of the President at Stanford University and by National Science Foundation Award \#0835614. We thank colleagues at Stanford University and at Tampere University for their feedback on an earlier draft of the manuscript. We also appreciate the critical and detailed feedback we received from two anonymous reviewers.

Open Access This article is distributed under the terms of the Creative Commons Attribution 4.0 International License (http://creativecommons.org/licenses/by/4.0/), which permits unrestricted use, distribution, and reproduction in any medium, provided you give appropriate credit to the original author(s) and the source, provide a link to the Creative Commons license, and indicate if changes were made.

\section{References}

Abbott, Andrew. 2001. The chaos of disciplines. Chicago, IL: The University of Chicago Press.

Aldrich, John H. 2014. Interdisciplinarity: Its role in a discipline-based academy. New York, NY: Oxford University Press.

Allen, Thomas J. 1984. Managing the flow of technology. Cambridge, MA: MIT Press.

Allen, Thomas J. 2007. Architecture and communication among product development engineers. California Management Review 49(2): 23-41.

Biancani, Susan, Daniel A. McFarland, and Linus Dahlander. 2014. The semiformal organization. Organization Science 25(5): 1306-1324.

Boardman, P. Craig, and Elizabeth A. Corley. 2008. University research centers and the composition of research collaborations. Research Policy 37: 900-913.

Boix Mansilla, Veronica. 2006. Interdisciplinary work at the frontier: An empirical examination of expert interdisciplinary epistemologies. Issues in Integrative Studies 24: 1-31.

Boix Mansilla, Veronica, Michèle Lamont, and Kyoko Sato. 2015. Shared cognitive-emotional-interactional platforms: Markers and conditions for successful interdisciplinary collaborations. Science, Technology, \& Human Values 41(4): 571-612.

Bozeman, Barry, and Craig Boardman. 2014. Research collaboration and team science: A state-of-theart review and agenda. Cham, Switzerland: Springer International Publishing.

Bruce, Ann, Catherine Lyall, Joyce Tait, and Robin Williams. 2004. Interdisciplinary integration in Europe: The case of the fifth framework programme. Futures 36(4): 457-470.

Burt, Ronald S. 2004. Structural holes and good ideas. American Journal of Sociology 110: 349-399. 
Calvert, Jane. 2010. Systems biology, interdisciplinarity and disciplinary identity. In Collaboration in new life sciences, eds. John N. Parker, Niki Vermeulen, and Bart Penders, 201-218. Farnham, UK: Ashgate Publishing.

Crow, Michael M. 2010. Organizing teaching and research to address the grand challenges of sustainable development. BioScience 60(7): 488-489.

Crow, Michael M., and William B. Dabars. 2014. Towards interdisciplinarity by design in the American research university. In University experiments in interdisciplinarity: Obstacles and opportunities, eds. Peter Weingart and Britta Padberg, 13-36. Bielefeld: Transcript Verlag.

Crow, Michael M., and William B. Dabars. 2015. Designing the new American university. Baltimore, MD: Johns Hopkins University Press.

Cummings, Jonathon N., and Sara Kiesler. 2007. Coordination costs and project outcomes in multi-university collaborations. Research Policy 36(10): 1620-1634.

Dahlander, Linus, and Daniel A. McFarland. 2013. Ties that last: Tie formation and persistence in research collaborations over time. Administrative Science Quarterly 58: 69-110.

Davis, Tim R.V. 1984. The influence of the physical environment in offices. Academy of Management Review 9(2): 271-283.

Geiger, Roger L. 1990. Organized research units-Their role in the development of university research. Journal of Higher Education 61: 1-19.

Getzels, J.W. 1975. Problem-finding and inventiveness of solutions. Journal of Creative Behavior 9: $12-18$.

Glaser, Barney G., and Anselm L. Strauss. 1967. The discovery of grounded theory: Strategies for qualitative research. Chicago, IL: Aldine Pub. Co.

Graff, H.J. 2015. Undisciplining knowledge: Interdisciplinarity in the twentieth century. Baltimore, MD: Johns Hopkins University Press.

Hackett, Edward J., and Diana R. Rhoten. 2009. The Snowbird charrette: Integrative interdisciplinary collaboration in environmental research design. Minerva 47(4):407-440.

Hampton, Stephanie E., and John N. Parker. 2011. Collaboration and productivity in scientific synthesis. BioScience 61(11): 900-910.

Holland, Dominic. 2014. Integrating knowledge through interdisciplinary research: Problems of theory and practice. London: Routledge.

Hollingsworth, Rogers, and Ellen Jane Hollingsworth. 2000. Major discoveries and biomedical research organizations: Perspectives on interdisciplinarity, nurturing leadership, and integrated structure and cultures. In Practising interdisciplinarity, eds. Peter Weingart and Nico Stehr, 215-244. Toronto, Canada: University of Toronto Press.

Jacobs, Jerry A., and Scott Frickel. 2009. Interdisciplinarity: A critical assessment. Annual Review of Sociology 35: 43-65.

Jacobs, Jerry A. 2013. In defense of disciplines: Interdisciplinarity and specialization in the research university. Chicago, IL: University of Chicago Press.

Kabo, Felichism W., Natalie Cotton-Nessler, Yongha Hwang, Margaret C. Levenstein, and Jason OwenSmith. 2014. Proximity effects on the dynamics and outcomes of scientific collaborations. Research Policy 43(9): 1469-1485.

Kagan, Jerome. 2009. The three cultures. Natural sciences, social sciences, and the humanities in the 21st century. Cambridge: Cambridge University Press.

Kaplan, Sarah, Jonathan Milde, and Ruth Schwartz Cowan. 2016. Symbiont practices in boundary spanning: Bridging the cognitive and political divides in interdisciplinary research. Academy of Management Journal 60(4): 1387-1414.

Klein, Julie Thompson. 2010. A taxonomy of interdisciplinarity. In The Oxford handbook of interdisciplinarity, eds. Robert Frodeman, Julie Thompson Klein, and Carl Mitcham, 15-30. Oxford: Oxford University Press.

Knorr-Cetina, Karin. 1999. Epistemic cultures: How the sciences make knowledge. Cambridge, MA: Harvard University Press.

Kuhn, Thomas S. 1970. The structure of scientific revolutions. Chicago, IL: University of Chicago Press.

Leahey, Erin, and Kathleen Montgomery. 2011. The meaning of regulation in a changing academic profession. In The American Academic Profession, ed. Joseph C. Hermanowicz, 295-311. Baltimore: The Johns Hopkins University Press.

Leahey, Erin, and James Moody. 2014. Sociological innovation through subfield integration. Social Currents 1(3): 228-256. 
Lengwiler, Martin. 2006. Between charisma and heuristics: Four styles of interdisciplinarity. Science and Public Policy 33(6): 423-434.

Lindvig, Katrine, and Line Hillersdal. 2019. Strategically unclear? Organizing interdisciplinarity in an excellence programme of interdisciplinary research in Denmark. Minerva 57(1): 23-46.

Marquardt, Wolfgang, and Thorsten Wilhelmy. 2014. "Cross the border, close the gap"-Reinventing the university as an interdisciplinary enterprise. In University experiments in interdisciplinarity: Obstacles and opportunities, eds. Peter Weingart and Britta Padberg, 13-36. Bielefeld: Transcript Verlag.

McBee, David J., and Erin Leahey. 2016. New directions in interdisciplinary training: Trials and tribulations. In Investigating interdisciplinary collaboration: Theory and practice across disciplines, eds. Scott Frickel, Mathieu Albert, and Barbara Prainsack, 27-46. Rutgers, NJ: Rutgers University Press.

McCarthy, John. 2004. Tackling the challenges of interdisciplinary biosciences. Nature Reviews Molecular Cell Biology 5: 933-937.

Mäkinen, Elina I. 2018. Complexity leadership theory and the leaders of transdisciplinary science. Informing Science: The International Journal of an Emerging Transdiscipline 21: 133-155.

Mäkinen, Elina I. 2019. The power of peer review on transdisciplinary discovery. Science, Technology, \& Human Values. https://doi.org/10.1177/0162243918822741

National Academies 2005. Facilitating interdisciplinary research. Washington, DC: National Academies Press.

Padberg, Britta. 2014. The Center for Interdisciplinary Research (ZiF)-Epistemic and institutional considerations. In University experiments in interdisciplinarity: Obstacles and opportunities, eds. Peter Weingart and Britta Padberg, 95-116. Bielefeld: Transcript Verlag.

Penders, Bart, Klasien Horstman, and Rein Vos. 2008. Walking the line between lab and computation: The "moist" zone. BioScience 58(8): 747-755.

Rawlings, Craig M., and Daniel A. McFarland. 2011. Influence flows in the academy: Using affiliation networks to assess peer effects among researchers. Social Science Research 40: 1001-1017.

Rhoten, Diana. 2005. Interdisciplinary research: Trend or transition. Items Issues 5: 6-11.

Stokols, Daniel, Kara L. Hall, Brandie K. Taylor, and Richard P. Moser. 2008a. The science of team science: Overview of the field and introduction to the supplement. American Journal of Preventive Medicine 35(2): 77-89.

Stokols, Daniel, Shalini Misra, Richard P. Moser, Kara L. Hall, and Brandie K. Taylor. 2008b. The ecology of team science: Understanding contextual influences on transdisciplinary collaboration. American Journal of Preventive Medicine 35(2): 96-115.

Strauss, Anselm L. 1987. Qualitative analysis for social scientists. Cambridge: Cambridge University Press.

Strober, Myra H. 2011. Interdisciplinary conversations: Challenging habits of thought. Stanford, CA: Stanford University Press.

Tushman, Michael L. 1977. Special boundary roles in the innovation process. Administrative Science Quarterly 22: 587-605.

Wuchty, Stefan, Benjamin F. Jones, and Brian Uzzi. 2007. The increasing dominance of teams in the production of knowledge. Science 316(5827): 1036-1039.

Yin, Robert K. 2008. Case study research: Design and methods. Beverly Hills, CA: Sage.

Publisher's Note Springer Nature remains neutral with regard to jurisdictional claims in published maps and institutional affiliations. 